\title{
Performing Cytoreductive Nephrectomy following Targeted Sunitinib Therapy for Metastatic Renal Cell Carcinoma: A Surgical Perspective
}

\author{
Greg L. Shaw ${ }^{\mathrm{a}}$ Mahreen Hussain ${ }^{\mathrm{a}}$ Rajesh Nair ${ }^{\mathrm{a}}$ John Bycroft ${ }^{\mathrm{a}}$ Luis Beltran ${ }^{\mathrm{a}}$ \\ James S.A. Green ${ }^{a}$ Thomas Powles ${ }^{b}$ John L. Peters ${ }^{a}$

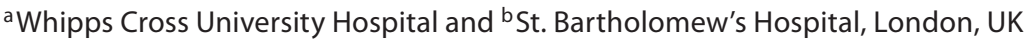

\section{Key Words}

Metastatic renal cell carcinoma $\cdot$ Cytoreductive

nephrectomy $\cdot$ Neoadjuvant sunitinib $\cdot$ Operative safety

\begin{abstract}
Objective: To describe for surgeons contemplating performing cytoreductive nephrectomy (CRN) on patients after neoadjuvant sunitinib compared to a benchmark of open radical nephrectomy, describing technical difficulties, safety and feasibility. Patients and Methods: We compared measurable surgical parameters and perioperative complications in 22 patients with metastatic renal cell carcinoma (mRCC) undergoing CRN after neoadjuvant sunitinib, with 28 patients who underwent open radical nephrectomy for non-metastatic disease (nmRCC). Results: Median blood loss (320 vs. $775 \mathrm{ml}$ ), median operative time (128 vs. $195 \mathrm{~min}$ ) and median length of stay ( 5 vs. 7 days) were greater in the $\mathrm{mRCC}$ group. Surgery after sunitinib was technically challenging due to fibrosis, loss of the tissue planes that usually facilitate radical nephrectomy and abnormal blood vessel formation. Side effects of sunitinib resulted in predictable complications. Conclusion: CRN after treatment with sunitinib is safe and feasible in our hands, although the surgery is more timeconsuming and technically demanding. A multidisciplinary approach is mandatory.

Copyright $\odot 2012$ S. Karger AG, Basel
\end{abstract}

\section{Introduction}

Renal cell carcinoma (RCC) is the commonest kidney cancer [1]. In the UK its incidence is rising, with 8,228 new cases in 2007 [2] and with $25 \%$ of cancers having metastasised at diagnosis [3]. 85\% have clear cell carcinoma. The prognosis is poor with a $23 \% 5$-year overall survival rate reported in the original study demonstrating superiority over interferon- $\alpha$ (IFN- $\alpha$ ). Herein, Motzer et al. [4] demonstrated that sunitinib improved median progression-free survival (11 vs. 5 months) and overall survival ( 26.4 vs. 21.6 months) in patients with metastatic RCC (mRCC). Following this work, targeted therapies are the standard of care for mRCC in the UK with NICE recommending sunitinib as first-line treatment for advanced or mRCC in fit patients [5].

In the immunotherapy era, two prospective randomised trials (SWOG 8949 [6] and EORTC 30947 [7]) comparing cytoreductive nephrectomy (CRN) followed by IFN- $\alpha$ versus IFN- $\alpha$ without surgery, demonstrated the utility of CRN in improving overall survival. A combined analysis of these SWOG and EORTC trials confirmed a longer median survival in the nephrectomy/ IFN- $\alpha$ group [8]. In theory, tumour bulk may act as a sink absorbing antibodies and anticancer cells [9] and/or tumour releasing pro-angiogenic factors (VEGF and PDGF)

\section{KARGER}

Fax +4161306 1234

E-Mail karger@karger.ch

www.karger.com
(C) 2012 S. Karger AG, Basel

0042-1138/12/0891-0083\$38.00/0

Accessible online at:

www.karger.com/uin
Mr. G.L. Shaw

University Department of Oncology

Box 279 (S4), Addenbrooke's Hospital

Cambridge CB2 0QQ (UK)

Tel. +44 7803158 770, E-Mail gregshaw@ doctors.org.uk 
Table 1. Patient characteristics

\begin{tabular}{lll}
\hline $\begin{array}{l}\text { Patient } \\
\text { demographics }\end{array}$ & $\begin{array}{l}\text { Open radical } \\
\text { nephrectomy } \\
\text { for nmRCC }\end{array}$ & $\begin{array}{l}\text { Cytoreductive } \\
\text { nephrectomy } \\
\text { for mRCC }\end{array}$ \\
\hline $\begin{array}{l}\text { Number of patients } \\
\text { Median age (range), years }\end{array}$ & 28 & 22 \\
Male & $20(71 \%)$ & $65(45-81)$ \\
pT stage & 0 & $17(77 \%)$ \\
T1a & 0 & 0 \\
T1b & $4(14 \%)$ & $1(4 \%)$ \\
T2a & $5(18 \%)$ & $3(14 \%)$ \\
T2b & $10(36 \%)$ & $12(55 \%)$ \\
T3a & $5(18 \%)$ & $3(14 \%)$ \\
T3b & 0 & 0 \\
T3c & $4(14 \%)$ & $2(9 \%)$ \\
T4 & & \\
\hline
\end{tabular}

Table 2. Surgical complications and operative outcomes

\begin{tabular}{lll}
\hline & $\begin{array}{l}\mathrm{nmRCC} \\
(\mathrm{n}=28)\end{array}$ & $\begin{array}{l}\mathrm{mRCC} \\
(\mathrm{n}=22)\end{array}$ \\
\hline $\begin{array}{l}\text { Surgical parameters } \\
\text { Median blood loss, } \mathrm{ml}\end{array}$ & $320(50-2,220)$ & $775(90-4,700)$ \\
$\begin{array}{l}\text { Operating time, min } \\
\text { Hospital stay, days }\end{array}$ & $128(66-390)$ & $195(70-420)$ \\
Intra-operative complications & $5(3-42)$ & $7(4-36)$ \\
Bowel-associated & 1 small bowel & 1 hemicolectomy \\
& enterotomy & 1 duodenal \\
& primary repair & reconstruction \\
Splenectomy & 0 & 1 \\
Hepatic resection & 0 & 1 \\
Vascular & 0 & 1 (IVC injury) \\
Post-operative complications & & \\
Clavien-Dindo grade $0 / 1$ & $84 \%$ & $80 \%$ \\
Clavien-Dindo grade $4 / 5$ & $9 \%$ & $15 \%$ \\
Death & 0 & 1 \\
Wound infection & 1 & 1 \\
Delayed wound healing & 1 & 1 (Addison's) \\
Endocrine disorders & 0 & 1 \\
Lymphocoele & 0 & \\
\hline
\end{tabular}

Ranges in parentheses.

[10]. The role of nephrectomy in the management of mRCC is less well established in the era of targeted therapies.

Debate continues as to which is best - adjuvant or neoadjuvant sunitinib. The EORTC 30073 phase 3 trial is designed to address this issue, with mRCC patients ran- domised to sunitinib then nephrectomy or CRN then sunitinib. There are at present 14 phase 2 trials of neoadjuvant treatment using various targeted therapies (including sunitinib, sorafenib, bevacizumab and everolimus) listed on clinicaltrials.gov. Those trial patients who are well enough after sunitinib will undergo CRN, performed by urologists who may have relatively little experience of nephrectomy in this context. Here we describe the experience of a single operating surgeon with this type of surgery through comparison with conventional radical nephrectomy, with which all urologists contemplating performing this type of surgery should be familiar. We have published data regarding the safety and efficacy of neoadjuvant sunitinib [11]. Here we focus on the surgical perspective of this approach.

\section{Methods}

Data was collected prospectively for 22 post-sunitinib patients with mRCC (as part of the SuMR trial - NCT01024205); all had received 3 cycles of neoadjuvant sunitinib prior to nephrectomy for biopsy confirmed clear cell RCC. CRN was performed 14 days after finishing sunitinib (day 28 cycle 3 ).

Data was collected retrospectively for the comparison group $(\mathrm{n}=28)$ that had undergone open radical nephrectomy for nonmetastatic RCC (nmRCC) from October 2008 to October 2010 by the same lead surgeon (J.L.P.).

Radical nephrectomy specimens were staged according to the Tumour Nodes Metastases (TNM) classification, by the same histopathologist (L.B.). Statistical significance was tested using Student's paired t test.

\section{Results}

Table 1 demonstrates preponderance in both groups of renal vein involvement (stage pT3a). There is no significant difference between the two groups of patients in terms of pathological T-stage or patient demographics.

Table 2 shows a comparison of surgical parameters and post-operative complications in the patients with nmRCC and those with mRCC. The results indicate significantly greater blood loss and operating time in the post-sunitinib group.

Although the surgery was more technically demanding in the mRCC group, the rate of post-operative complications was similar. One death occurred in the mRCC group. This patient was known to have extensive lung metastases prior to undergoing surgery. He opted for surgery despite being fully informed regarding the significant risks and limited potential benefits of surgery. One pa- 
Fig. 1. a, b Contrast-enhanced coronal section of CT scans of two typical post-sunitinib tumours. Large tumour size with extensive necrosis and fibrosis is demonstrated. c, d Photographs of surgical specimens post-sunitinib demonstrating extensive fibrosis around the periphery of the kidney and necrosis of the tumour.
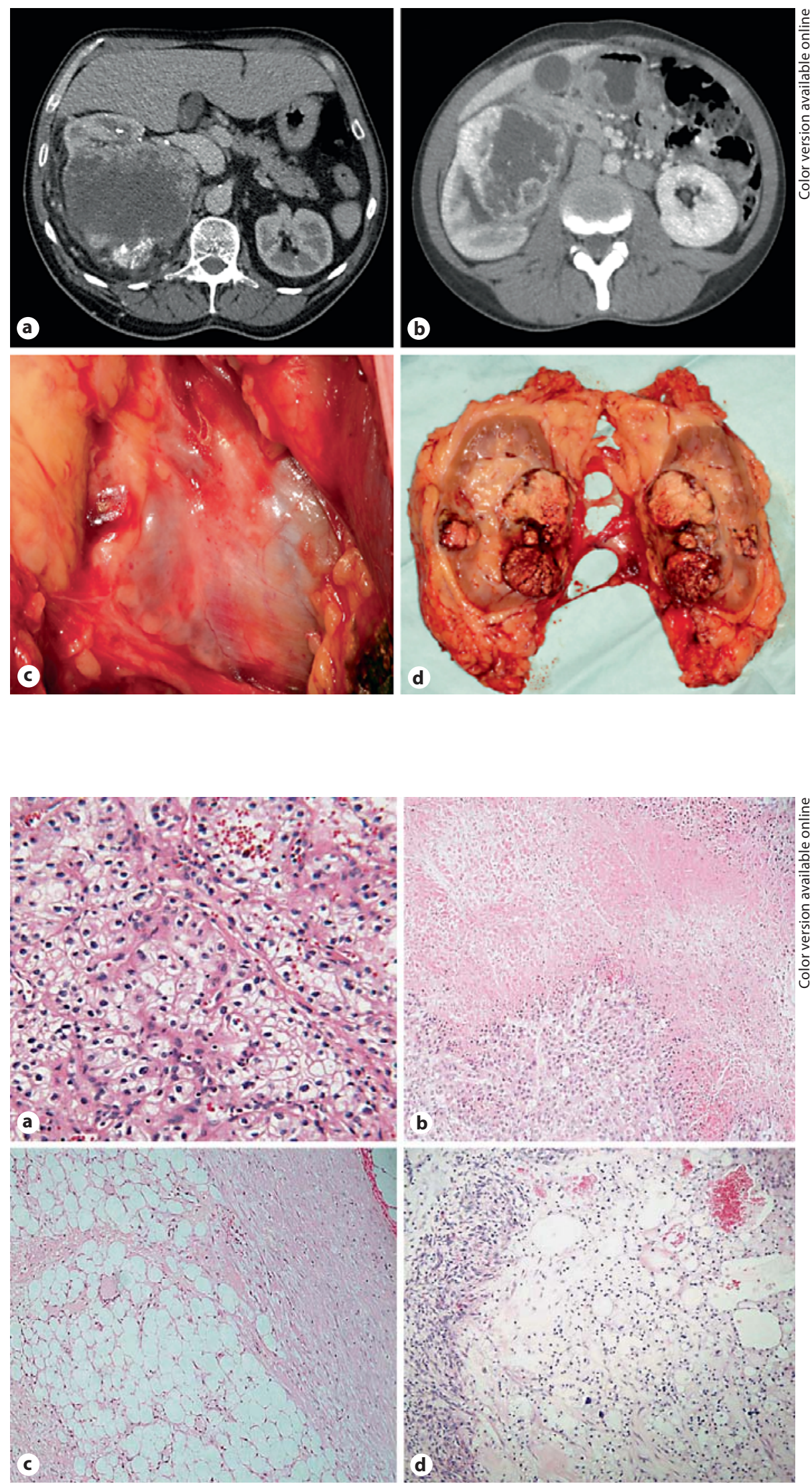

Fig. 2. a Histology of conventional untreated clear cell renal carcinoma $(\times 100)$. b-d Clear cell carcinoma after treatment with sunitinib $(\times 200)$ : necrosis within the tumour (b), fibrosis in the peri-renal fat (c), and neovascularisation with a rim of newly formed capillaries surrounding the tumour (d).

Performing Cytoreductive Nephrectomy following Sunitinib 
Table 3. Implications of neo-adjuvant sunitinib on peri-operative care during CRN

\begin{tabular}{lll}
\hline & Predictable effect of sunitinib & Implications for peri-operative management \\
\hline Pre-operative & $\begin{array}{l}\text { Anaemia } \\
\text { Thrombocytopenia } \\
\text { Neutropenia }\end{array}$ & $\begin{array}{l}\text { Pre-operative transfusion } \\
\text { Clotting dysfunction, platelet transfusion } \\
\text { Vigilance regarding asepsis/antibiotic prophylaxis }\end{array}$ \\
\hline Anaesthetic & LV dysfunction & $\begin{array}{l}\text { Invasive monitoring and post-operative HDU } \\
\text { Interaction with ondansetron, droperidol (arrhythmia) }\end{array}$ \\
& $\begin{array}{l}\text { Pypertension } \\
\downarrow \text { Efficacy of analgesics and antibiotics }\end{array}$ & \\
\hline Intra-operative & Haemorrhage & Poor intra-operative vision, intra-operative blood/platelet transfusion \\
\hline Post-operative & $\downarrow$ VEGF activity & $\begin{array}{l}\text { Delayed wound healing (theoretical) } \\
\text { Precipitated Addisonian crisis }\end{array}$ \\
& Hypothyroidism & Prophylaxis, early LMWH treatment and mobilisation \\
& Venous thromboembolism & \\
\hline Histopathological & Fibrosis & Prolonged operative time, increased blood loss, increased risk of \\
& Necrosis & damage to adjacent viscera \\
\hline
\end{tabular}

tient had an Addisonian crisis post-operatively, probably due to adrenal suppression resulting from sunitinib treatment. This was managed successfully with steroid, fluid and electrolyte replacement.

Tumour necrosis and desmoplastic reaction, as seen in the post-sunitinib group, resulted in thickening of the capsule with fusing of tissue planes, making surgery technically more challenging with more frequent damage to adjacent viscera due to dense fibrotic adhesions. In 1 patient a simple enterotomy was made in the small bowel and repaired primarily. Another required duodenal resection following injury. A splenectomy was performed in 1 patient and (minimal) hepatic resection for bleeding in another. One patient required primary repair of an injury to the infra-hepatic inferior vena cava. This compares with one splenectomy and one small bowel enterotomy in the nmRCC group. Similar numbers of post-operative complications occurred in each group (table 2).

Histopathological examination demonstrated necrosis in $94 \%$ of patients; this was extensive ( $>30 \%$ of tumour volume) in 50\%. Figure 1a and b demonstrate typical CT appearances with central necrosis, figure $1 \mathrm{c}$ and d demonstrate the dense fibrosis found at surgery (fig. 1c) and after bisection of the resected kidney (fig. 1d). Hyalinisation was seen in $91 \%$ and neo-vascularisation in $74 \%$ of patients after sunitinib treatment. Figure $2 \mathrm{a}$ is a highpower photomicrograph of the histology (HE stain) of clear cell carcinoma for comparison with figure $2 \mathrm{~b}-\mathrm{d}$ which are photomicrographs of tumours after sunitinib with abnormal, thin-walled vasculature. A propensity for contact bleeding was common at CRN.

\section{Discussion}

There is no doubt that anti-angiogenic tyrosine kinase inhibitors have revolutionised the management of mRCC. With large-scale multicentre trials enrolling across Europe, more urological surgeons will be performing surgery in this setting. In table 3 we consider the predictable effects of sunitinib with respect to implications regarding the peri-operative care of these patients.

The thrombocytopenia and anaemia associated with sunitinib treatment as well as disseminated malignancy necessitated pre-operative optimisation with transfusion of blood products, in preparation for surgery in several patients.

Left ventricular dysfunction, prolongation of QT interval and hypertension all have implications for the anaesthetic, and in all post-sunitinib patients LV function was quantified with an echocardiogram pre-operatively.

The mechanism by which sunitinib causes hypertension may be through VEGF and PDGF inhibition decreasing vascular compliance and decreasing microvessel density leading to increased peripheral vascular resistance. The altered liver function seen with sunitinib resulting in altered drug metabolism necessitated care- 
ful post-operative antibiotic and analgesic titration. Adrenal insufficiency can result from sunitinib therapy, and in 1 patient surgery precipitated an Addisonian crisis requiring aggressive steroid, fluid and electrolyte replacement.

Sunitinib inhibits tyrosine kinases anti-proliferative and anti-angiogenic effects. Our concerns regarding post-operative wound healing were unfounded despite pre-clinical evidence of delayed wound healing with sunitinib [12]. There was no wound dehiscence in either group.

Sunitinib is pro-thrombotic. In the immediate postoperative period this and the presence of disseminated malignancy renders the patients susceptible to thrombosis. We did not encounter any peri-operative thromboembolism. Prophylaxis was undertaken with the pre-operative application of thromboembolic deterrent stockings, intra- and post-operative pneumatic calf compression and post-operative subcutaneous low-molecular-weight heparin, with early mobilisation.

Published data regarding CRN after targeted therapy for metastatic clear cell RCC is limited but includes one report in which 44 patients were treated with a variety of targeted therapies before CRN. A total of 39 complications occurred in 17 (39\%) patients treated with preoperative targeted molecular therapy and in $16(28 \%)$ who underwent up-front resection $(p=0.287)$ [13]. A second retrospective review of 19 patients treated with sunitinib, sorafenib or bevacizumab + interleukin and subsequent CRN. One patient had a significant intraoperative haemorrhage and disseminated intravascular coagulopathy from a concomitant liver resection. An anastomotic bowel leak and abscess were noted postoperatively in another patient who underwent en bloc resection of a retroperitoneal recurrence and adjacent colon. Two patients (11\%) had minor wound complica- tions, including a wound seroma and a ventral hernia [14]. A third describes 14 CRNs after sunitinib or sorafenib. These authors found that intraoperative adhesions were problematic, but in accordance with our findings did not observe any wound-healing problems [15]. This report is the first to describe the surgical perspective of treating patients treated only with sunitinib preceding CRN and reflects move towards sunitinib, rather than other tyrosine kinase inhibitors, as first-line treatment in metastatic RCC.

Although surgical complications and outcomes seem comparable between those patients who underwent open radical nephrectomy for nmRCC and those who underwent CRN post-sunitinib, we advocate interdisciplinary co-operation where surgical difficulties can be predicted based on relation to adjacent organs. Minimum requirements include: rigorous pre-operative assessment and patient optimisation, senior anaesthetic involvement, careful monitoring of post-operative analgesia and optimal surgical planning with assured support from general and vascular surgical colleagues. We hope that these data will be of value to the surgical team preparing to undertake this kind of surgery.

\section{Conclusion}

The potentially serious adverse effects associated with neoadjuvant sunitinib make subsequent CRN surgically and anaesthetically challenging. However, with adequate preparation and technique the risks might be minimised.

\section{Disclosure Statement}

The authors have no conflicts of interest to disclose.

\section{References}

1 Kovacs G, Akhtar M, Beckwith BJ, et al: The Heidelberg classification of renal cell tumours. J Pathol 1997;183:131-133.

2 Office for National Statistics. Cancer Statistics Registrations: Registrations of cancer diagnosed in 2007, England. Series MB1 No. 38. 2010, National Statistics: London and Mortality Statistics: 2008. Available from www.statistics.gov.uk.

Performing Cytoreductive Nephrectomy following Sunitinib
3 Bex A, Jonasch E, Kirkali Z, et al: Integrating surgery with targeted therapies for renal cell carcinoma: current evidence and ongoing trials. Eur Urol 2010;58:819-828.

4 Motzer RJ, Hutson TE, Tomczak P, et al: Sunitinib versus interferon alfa in metastatic renal-cell carcinoma. N Engl J Med 2007; 356:115-124.

5 Tomlins SA, Rhodes DR, Perner S, et al: Recurrent fusion of TMPRSS2 and ETS transcription factor genes in prostate cancer. Science $2005 ; 310: 644-648$.
6 Flanigan RC, Salmon SE, Blumenstein BA, et al: Nephrectomy followed by interferon alfa$2 \mathrm{~b}$ compared with interferon alfa- $2 \mathrm{~b}$ alone for metastatic renal-cell cancer. N Engl J Med 2001;345:1655-1659.

7 Mickisch GH, Garin A, van Poppel H, de Prijck L, Sylvester R: Radical nephrectomy plus interferon-alfa-based immunotherapy compared with interferon alfa alone in metastatic renal-cell carcinoma: a randomised trial. Lancet 2001;358:966-970. 
8 Flanigan RC, Mickisch G, Sylvester R, Tangen C, Van Poppel H, Crawford ED: Cytoreductive nephrectomy in patients with metastatic renal cancer: a combined analysis. J Urol 2004;171:1071-1076.

-9 Abel EJ, Wood CG: Cytoreductive nephrectomy for metastatic RCC in the era of targeted therapy. Nat Rev Urol 2009;6:375-383.

10 Slaton JW, Inoue K, Perrotte P, et al: Expression levels of genes that regulate metastasis and angiogenesis correlate with advanced pathological stage of renal cell carcinoma. Am J Pathol 2001;158:735-743.
Josephs D, Hutson TE, Cowey CL, et al: Efficacy and toxicity of sunitinib in patients with metastatic renal cell carcinoma with severe renal impairment or on haemodialysis. BJU Int 2011;108:1279-1283.

12 Roman CD, Choy H, Nanney L, et al: Vascular endothelial growth factor-mediated angiogenesis inhibition and postoperative wound healing in rats. J Surg Res 2002;105: 43-47.

13 Margulis V, Matin SF, Tannir N, et al: Surgical morbidity associated with administration of targeted molecular therapies before cytoreductive nephrectomy or resection of locally recurrent renal cell carcinoma. J Urol 2008;180:94-98.
14 Thomas AA, Rini BI, Stephenson AJ, et al: Surgical resection of renal cell carcinoma after targeted therapy. J Urol 2009;182:881886.

15 Harshman LC, Yu RJ, Allen GI, Srinivas S, Gill HS, Chung BI: Surgical outcomes and complications associated with presurgical tyrosine kinase inhibition for advanced renal cell carcinoma. Urol Oncol 2011, E-pub ahead of print. 